\title{
AC-DC Converter Operation for Active Sinusoidal Line Current
}

\author{
Ibrahim Fatouh El-Sayed
}

Faculty of Engineering and Technology, Helfain Univrsity, Cairo, Egypt

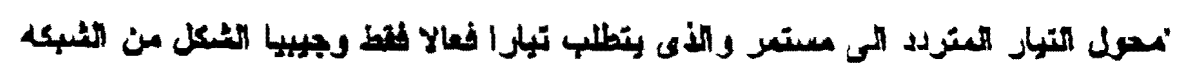

"الكمريثنة

ألخلاصــــــ :

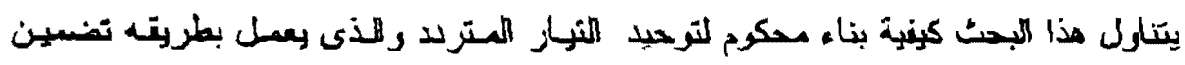

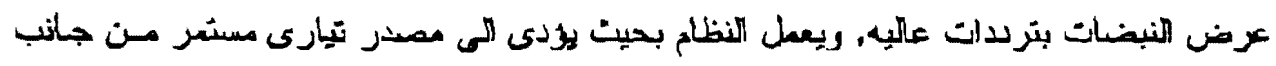

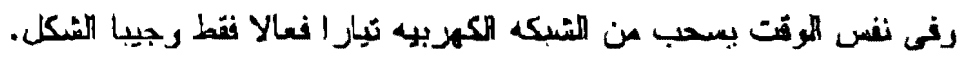

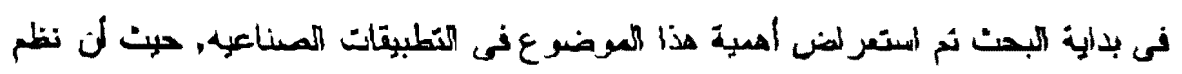

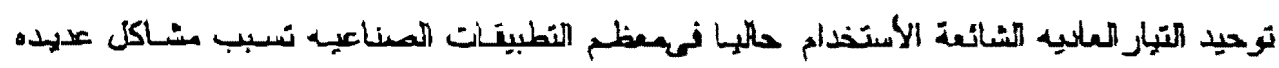

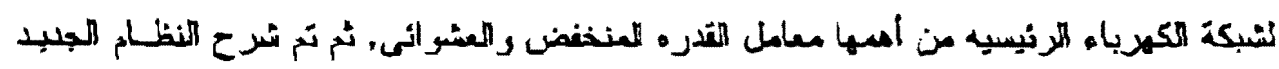

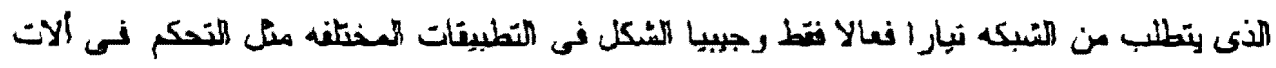

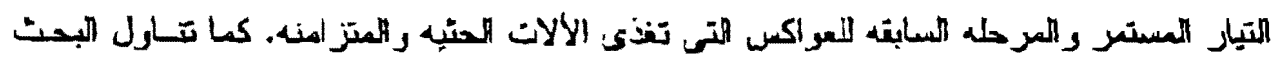

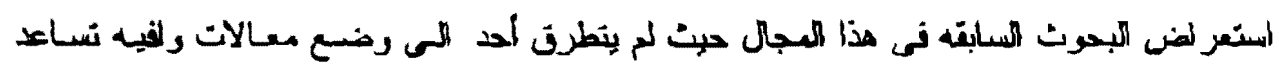

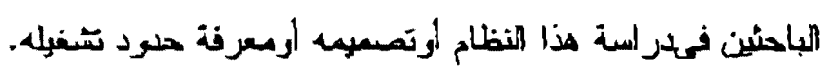

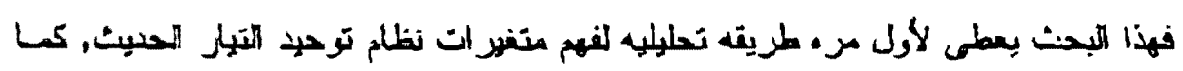

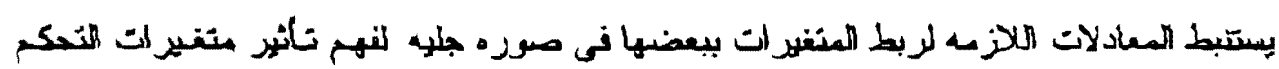

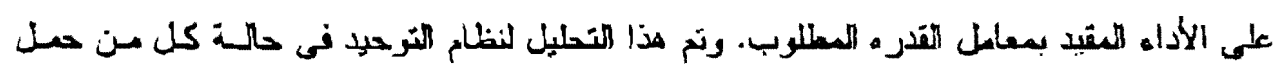

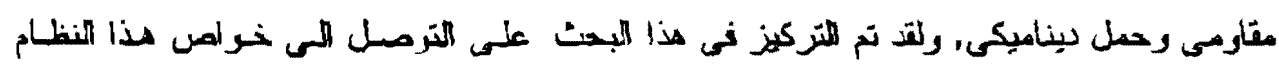

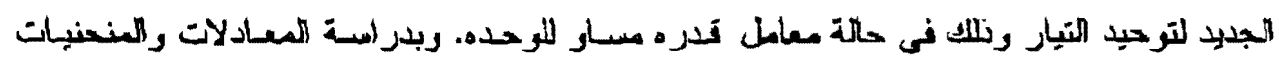

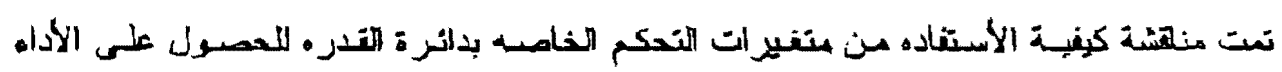

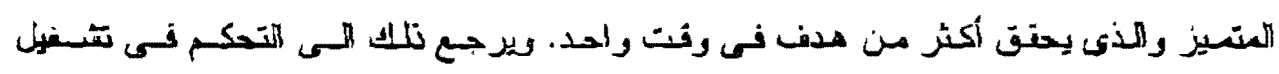

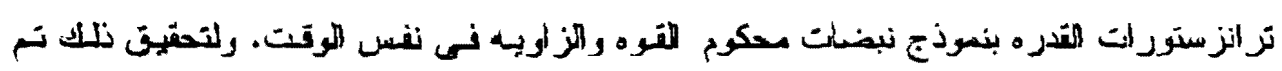

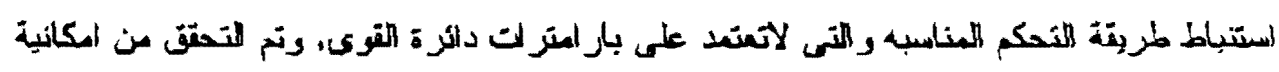

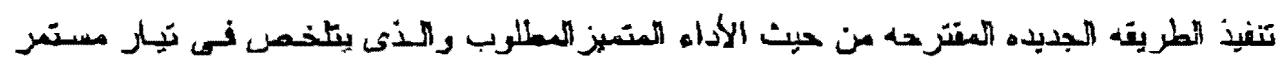

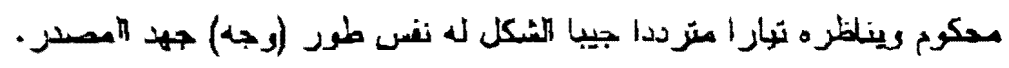




\begin{abstract}
The paper describes and implements a stand-alone, unity power factor, consrollable current source comventer system. It is based on high frequency PWM lechnique. The converter topology is chosen to operate for both inverter and rectifier modes. Frrsty, the principle of operation is discussed. Then, the presented AC-DC converter that demands only sinusoidal active current is studied. Most feabures of the converter are clearly interpreted for resistive and dynamic loads. On the basis of the given analysis, the paper provides PWM converter design guidelines for unity power factor operation. Also, a novel control strategy is proposed, which allows to fulfill all the specifications; in perticular zero reactive power demand and very low distorted line currents have been guaranteed. The proposed method in this paper utilizes simultaneously the control variables: modulation index $D$ (variable PWM pattern) and power angle 8 (position of the PWM pattern). The instantaneous control for both achieves high-dynamic response and insensitiveness to parameter variations and disturbances. Also, the presented control structure employs power factor adjustment capability. This development provides a low cost solution, where no digital signal processors or large memories for the PWM generation are required. Results from device level PSPICE confinm the vatidity of the proposed method and the performed analysis. The proposed system can be utilized for power conditioning, DC and $\mathrm{AC}$ drive applications.
\end{abstract}

\title{
1. INTRODUCTION
}

Traditional power electronic systems are the main reason for harmonic pollution. This pollution may lead to destructive resonance beside many other drawbacks for the electrical distribution systems. Most variable speed drive applications get its power via $A C$ to $D C$ converters. Normally phase-controlled thyristors converters have been extensively used because of there control simplicity. However, the line currents drawn by such cunverters have distorted waves those posses hamonic and reactive power. On the other hand, the harmoric contents and the reactive power are load dependent. Many attempts were introduced to reduce such drawbacks. For example inpur filters are used to reduce imput harmonics, also a compensating system can be used for power factor improvement. Another approaches uses an additional popver electronic schemes such as active filters [1]-[5] and reactive power compensators [6]-[8] that adapt itself with the AC-DC converters to overcome its drawbacks. For these approaches, it is difficult to eliminate all harmonics. Also, the load transients may cause difficulties for compensation process. Moreover, the required additional components increase system complexity that reduces its use as a low-cost option.

With the recent developed power electronic devices, a better rectifier approach can be proposed in which the requirements are not only the output magnitude and shape but also the input current. The controller modulates the converter switching devices with high frequency instead of a single turn-on and turn-off per half cycle.

The old approach makes eye only on the ourput state (current or voltage) and thereby the converter satisfies the output requirement with non sinusoidal line currents. The recent developed approach uses PWM technique for rectifier schernes. It can offer several advanced features such as sinusoidal imput current at unity power factor and simultaneous high quality DC output. This in tum results in reduced current ripple and reduced $A C$ voltage distortion in 
the grid and thereby contributes to overall improved performance. The grid sinusoidal active current reduces the losses and magnetic noise in the power transfommers. The size of the passive elements in the $A C$ side is considerably reduced due to PWM operation. Also, this approach can preserve its high performance features even under unbalance in the input supply that may be frequent, particularty in weak $A C$ systems. Thus both input and output control capability of such PWM controlled AC-DC converters make it very suitable for applications such as magnet power supplies, DC motor drives, controlled voltage and current inverters, reactive power control, and unity interactive wind and photo voltaic systems. The new generation of pulse width modulated controlled rectifiers has been widely studied. The expected converter is the one that stand alone with good performance level in terms of low harmonic distortion, power factor adjustment capability, power reversal, and good dynamic response.

Fig. 1 shows the general schematic circuit for PWM converter. The common factor of the PWM controlled converters is the method used in controlling the ourput state which is kept close to the desired value. The enor either controls the $A C$ input current or the converter back modulated voltage Vm. In general, the optimal PWM pattern is being adjusted to satisfy the system requirements.

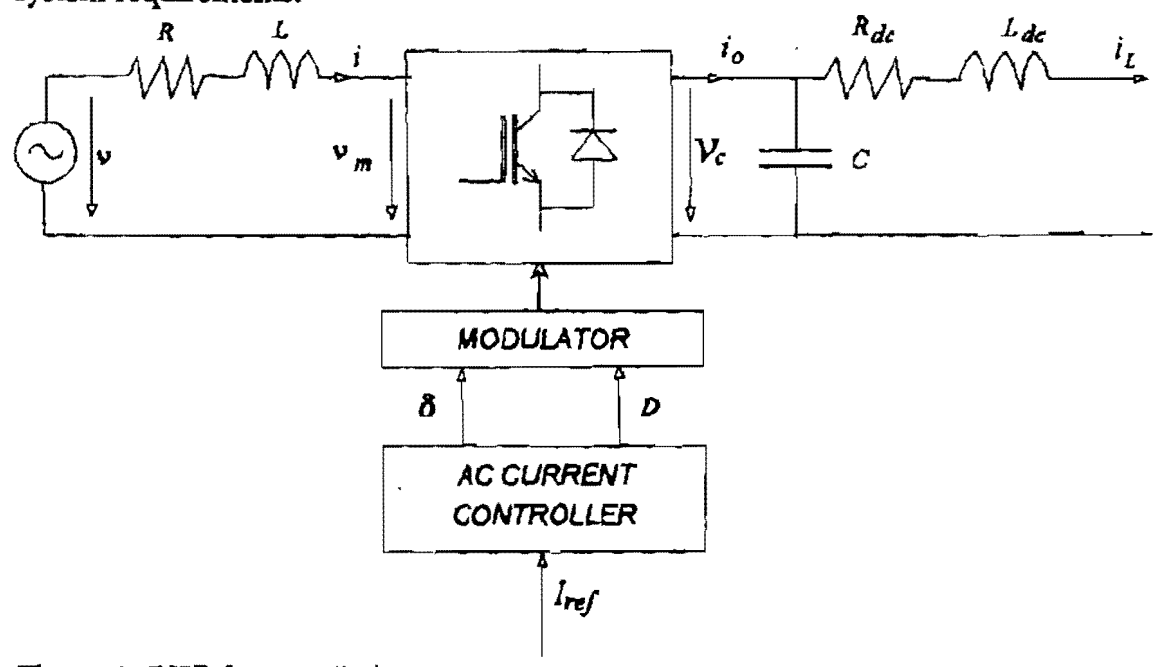

Figure 1: PWM controlled current corrvette.

Regarding the switching pattern generation and positioning related research papers have been continuousty appearing which signifies the importance and complexity of this subject [9]. Previous recent works [7], [10]-[13] are so much focused on system linearization or solving nonlinear dynamic equations on-line. These require multi-DSP system operating in parallel. However, up to the present, these control strategies are of the static typo.

In this work, the proposed controlled current comverter that draws sinusoidal active current is analysed and implemented. The analyses is focused on unity power factor operation for resistive and dynamic loads. The presented method can be used to understand clearly the system capability and the relations between the control variables. Where it can be used for developing different control strategies. Also, the paper presents a new simple control strategy that satisfies unity power factor, and sinusoidal current in addition to output DC-current control. Finally, the real control method and power circuit have been implemented using Pspice for verification. 


\section{PRINCIPLE OF OPERATION}

Assuming that the high-order switching harmonics do not contribute much to the fundamental components, the equivalent power circuit for $A C$ and DC sides is shown in Fig. 2 . In this figure, $V$ is the fundamental $\mathrm{ms}$ source voltage. $V m$ is $\mathrm{rms}$ value of the fundamental wave generated by pulse width modulation for the capacitor DC voltage. $R$ and $L$ are the resistance and inductance inserted between the converter circuit and the $A C$ source. The inductance $L$ is necessary to filter the high frequency switching of the used PWM pattern. The cursent source Io impresses current segments of the $A C$ side current $i$ to the DC circuit. Therefore, the DC capacitor $C$ is necessary for decoupling the instantaneous reaction between the DC load current iL and the current source $i o$.
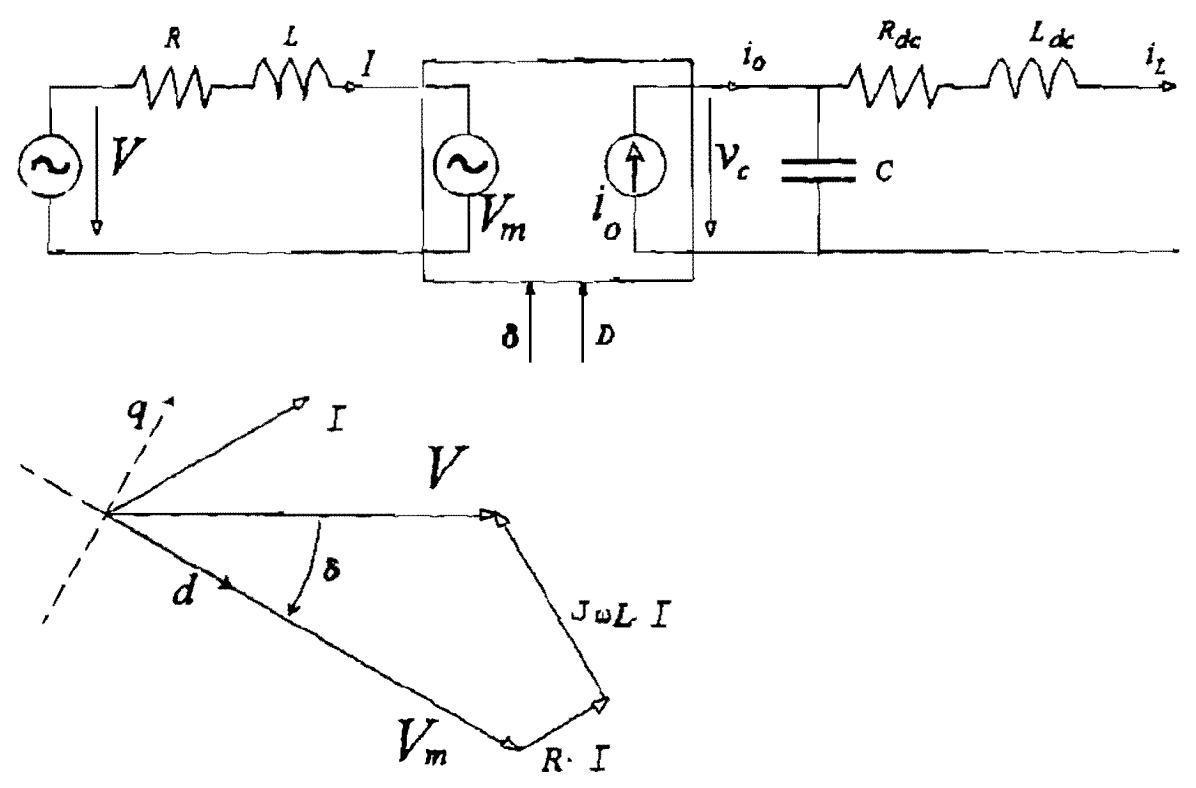

Figure 2: Equivalent circuit and phasor diagram.

The magnitude Vm depends on the capacitor average $D C$ voltage $\mathrm{Vc}$ and the modulation ratio $m$. Assuming full utilization of the power circuit where over modulation range can be used, then the value of $\mathrm{Vm}$ can be expressed as:

$V_{\mathrm{m}}=D . \mathrm{V}_{\mathrm{c}}$

The control variable $D$ (modulation index) has a nonlinear relation with the modulation ratio $m$.

As shown in Fig. 1, and 2, the switching PWM pattern generated by the modulator controls the voltage phasor $V_{\mathrm{m}}$. Where, the modulation index $D$, results by the used PWM switching pattern, affects the magnitude $\mathrm{Vm}$. While its position relative to the supply voltage defines the power angle $\delta$. Hence the motulator with the power scheme shown in Fig. 1 controts the amount and direction of the power flow transferred between $A C$ and $D C$ sices. For negative power angle ( $V / \mathrm{m}$ lags $V$ ), the power flow goes from the $\mathrm{AC}$ to the $\mathrm{DC}$ side and for positive power angle the power flows in the opposite direction. 
A system control method that is based on the unchangeable predetermined PWM switching pattern is proposed in [14], where the modulation index $D$ is held constant to achieve linear relation between the average capacitor voltage $V c$ and $V m$. However, there are still nonlinear relations that should be processed. Also, the non-utilization of control variable $D$ limits the system control capability, where the power factor is load dependent and, hence, is not constant.

It is important to state here that the presented control method in this paper utilizes simultaneousty the control variables: modulation index $D$ (variable PWM pattern) and power angle 8 (position of the PWM pattem). The main task for the presented controller is to control the phasor V/m referred to the source voltage through the AC current and source wrveform template to satisfy the requirements: controlling the DC load current with zero reactive power. The presented analysis shows that the relations between the above mentioned control variables and different DC load current for unity power factor are nonlinear. With these characteristics, it is difficult to achieve the requirements using on line computations. This problem is solved here by using an intelligent hysteresis controller for the input AC current. It can force the desired $A C$ current efficienthy and instantaneoushy to follow the reference wave by the proposed trysteresis controller in [15]. Then, without computations for PWM patterns and with only building the desired AC current wave that has the source voltage template, the DC load current can be controlled with input sinusoidal active current. The amplitude of the reference sinusoidal current is generated by the DC current controller. This control structure can drive the power circuit for both rectifier and irventer operations. When the sign of the current error signal is positive, the controller builds a reference $A C$ current wave that be in phase with the source voltage forcing the power circuit for rectifier operation. But when the error sign is negative, the reference $A C$ current wave rill be inverted for inverter operation.

\section{ANALYSIS OF THE CONVERTER}

For AC side, the phasor diagram shown in Fig. 2 establishes operating conditions between the source phasor $V$ and the converter terminal phasor $V \mathrm{~m}$. Also this phasor diagram can be expressed in $d-q$ frame as:

$$
\begin{aligned}
& R \cdot \mathrm{Id}-X \cdot \mathrm{Iq}_{\mathrm{q}}=\mathrm{Vd}-\mathrm{V}_{\mathrm{md}} \\
& X \text { Id }+R \cdot \mathrm{Iq}_{\mathrm{q}}=\mathrm{V}_{\mathrm{q}}-\mathrm{V}_{\mathrm{mq}} \\
& \text { where } \\
& \mathrm{V}_{\mathrm{d}}=\mathrm{V} \cdot \cos (8) \\
& \mathrm{V}_{\mathrm{q}}=\mathrm{V} \cdot \sin (-8) \\
& \mathrm{V}_{\mathrm{md}}=\mathrm{V}_{\mathrm{m}} \\
& \mathrm{V}_{\mathrm{mq}}=0
\end{aligned}
$$

Clearty, the DC-side comverier output current io controls the capacitor voltage level and the load current $i L$. This current sabsfies the instantaneous power balance equation between the AC side and the DC side of the converter circuit that can be written as follows:

$v_{\mathrm{c}} . i_{\mathrm{o}}=v_{\mathrm{md}} . i_{\mathrm{d}}+v_{\mathrm{mq}} . i_{\mathrm{q}}$

For steady state operation, the average DC capacitor voltage reaches a particular equilibrium value, which means that the average DC load current IL becomes equal to the average value $l o$. Then, the power balance equation (8) can be written for steady state as:

$$
\text { Vc. IL }=\mathrm{V} \text { md .Id }+V_{m q} \cdot I_{q}
$$


For simplicity, the parasitic resistance $R s$ and $R d c$ are omitted for the following analysia. By using Eq. (1), (2)-(9), it is possible to derive the relations between $D C$ output current $I L$ and the input control variables $(D, \delta)$.

$L=D \cdot I d=(D \cdot V / X) \cdot \sin (-8)$

\subsection{Resisttive load characteristics}

The relation between the $D C$ output voltage $\mathrm{V}_{c}$ and the input control variables $(D, \delta)$ for resistive load can be obtained using Eq.(10).

$V_{c}=(D \cdot V \cdot R U X) \cdot \sin (-8)$

Also, the active and reactive powers drawn from the AC source are:

$$
\begin{aligned}
& \begin{aligned}
\mathrm{P} & =\mathrm{Vd} \cdot \mathrm{Id}+\mathrm{Vq} \cdot \mathrm{Iq} \\
& =\left(a \cdot \mathrm{V}^{2} / X\right) \cdot \sin ^{2}(8) \\
\mathrm{Q} & =\mathrm{Vq} \cdot \mathrm{Id}-\mathrm{Vd} \cdot \mathrm{Iq} \\
& =\left(\mathrm{V}^{2} / X\right) \cdot[1-a \cdot \sin (8) \cdot \cos (8)]
\end{aligned} \\
& \text { where } \\
& \begin{aligned}
a & =(R L / X) \cdot D^{2}
\end{aligned}
\end{aligned}
$$

Fig. 3 shows the $\mathrm{P}-8$ and $\mathrm{Q}-8$ relations for different $a$ 's. It can be seen that the constant $a$ should be greater than 2 for zeto reactive power operation.
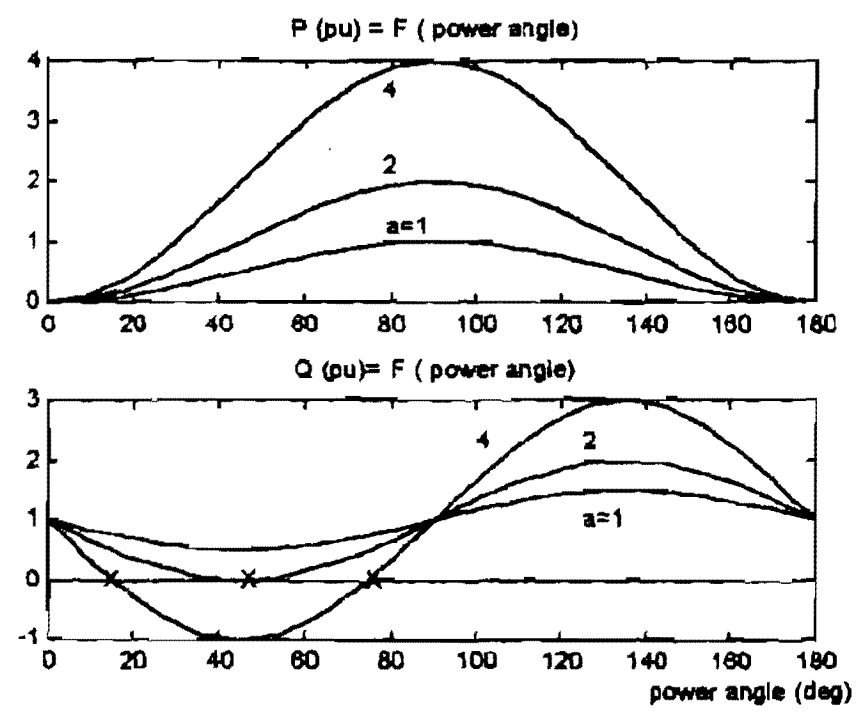

Figure 3: Active and reactive power (resistive load).

There are two possible power angles $(81, \delta 2)$ for unity power factor operation. These power angles can be obtained from Eq.(13) when $Q=0$.

$\delta_{1}=0.5 \cdot \arcsin (2 / a)$ 
$\delta_{2}=90^{\circ}-0.5 \cdot \arcsin (2 / a)$

The DC laad power of (12) for unity power factor conditions of (15), and (16) becomes

$P_{1,2}=\left(a \cdot V^{2} / X\right) \cdot \sin ^{2}\left(\delta_{1,2}\right)$

It is clear that the relation between the control variables are nonlinear. For the same value of the constant $a$, there are two possible values for output power $\mathrm{P}$ and two possible vahues for the control variable 8 . Equations (14)-(16) allow us to plot the relations between the control variables $\&$, and $D$ required for unity power factor condition.

Fig 4 showy $D-8$ curves for different values of $R E X$. Clearly, the control range of the modulation index $D$ and power angle 8 depend on the ratio between the load resistance $R L$ and the $\mathrm{AC}$ side inductor impedance $X$. The possible ranges for these control variables determine the control capalitity of the PWM converter for unity power factor operation.

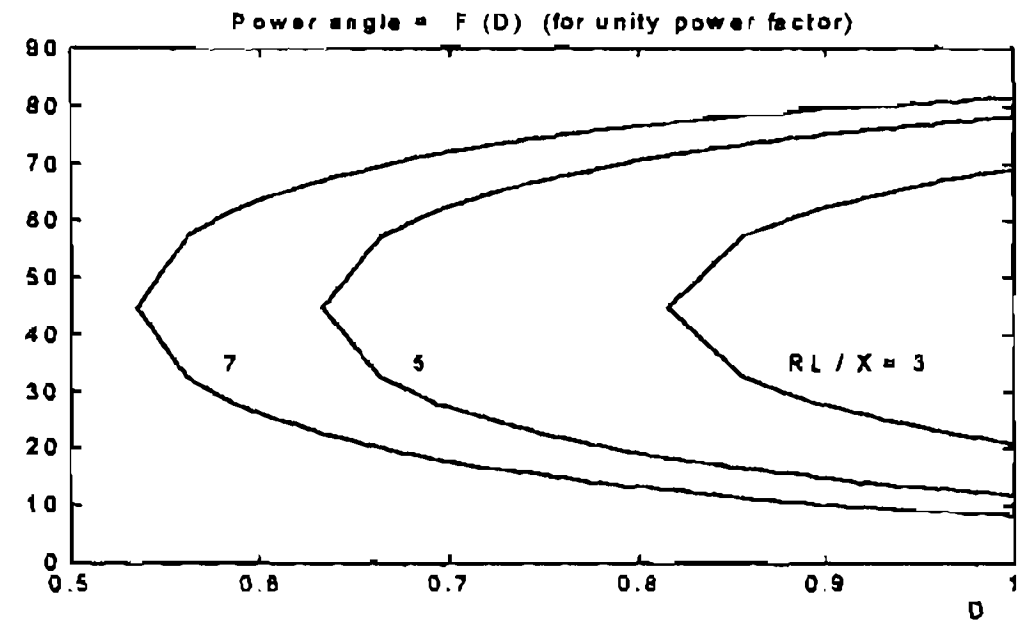

Figure 4: Control variables relation (resistive load).

Considering $V$ and $V / X$ as base values for voltage and current, the perunit load current and capacitor voltage using Eq. (10), (11), (15), and (16) are shown in Fig. S. It can be seen that for given $R L$, the source inductance determines the DC load current range that can be provided under unity power factor operation. Note that it is possible to get operations outside this range but on the expense of power factor different from unity.

\subsection{Controlled current characteristics}

The PWM converter can operate as ideal controlled current with unity power factor independent of the DC voltage level. The control variables determined by the PWM switching funcion forces the system to satisfy the requirements. The system capability depends on the circuit parameters. In case of dynamic load the power circuit also allows negative DC current flow (inverter operation) when the reference current is negative. This regeneration occurs while the DC capacitor voltage is kept positive. Hence the transient response for the DC current is determined mainly by the DC smoothing inductor. 

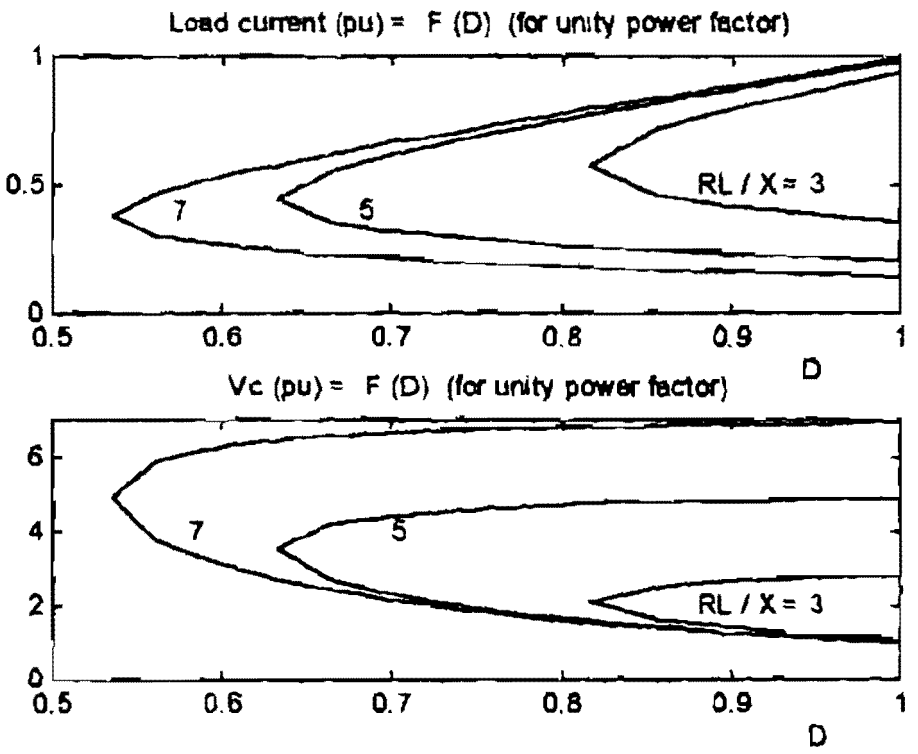

Figure 5: Load current and voltage capability (resistive load).

If the load has a voltage level of $V_{c o}$, the perunit reactive power $Q$ becomes

$Q=1-b \cdot \cos (\delta)$

where

$b=\left(\mathrm{V}_{\mathrm{co}} / \mathrm{V}\right) \cdot D$

Clearly, for constant power angle, the reactive power is linearly dependent with $b$ or equivalently $D$. To control the load current and the reactive power at the same time, both control variables $\delta$ and $D$ should be used as shown in Eq. (10), (18), and (19).

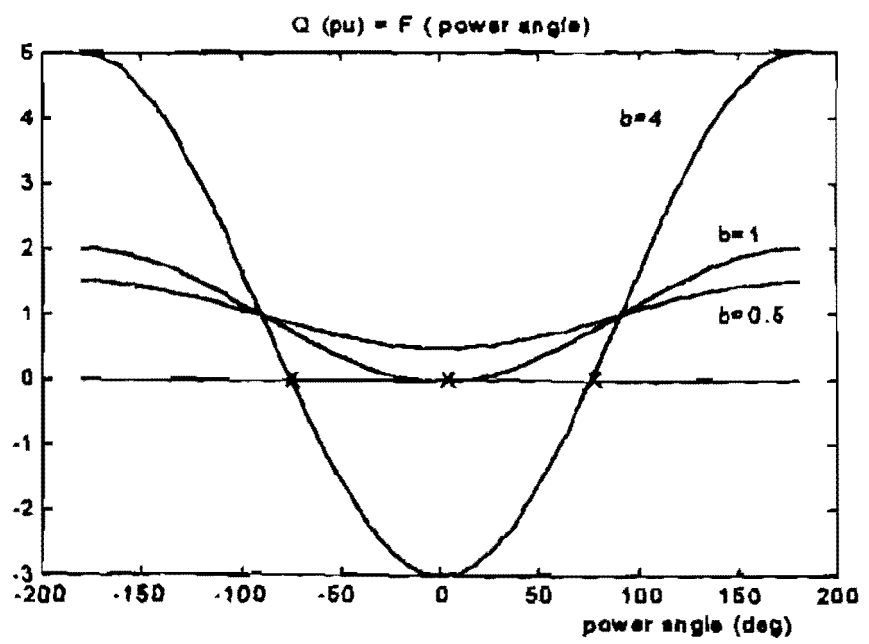

Figure 6: Reactive power (dynamic load). 
Fig. 6 shows the perunit reactive power for different values of $b$. For zero reactive power operation, $b$ should be greater than 1 . There are two possible power angles $(\delta 1,82)$ for unity power factor operation. The positive power angle $\delta$ is for regenerative operation, while the negative value for rectifier operation.

The constraint equation for zero reactive power is obtained from eq. (18), and (19) to be

$\mathrm{D}=(\mathrm{V} c \mathrm{o} / \mathrm{V}) \cdot \cos (8)$

If the constraint equation (20) is considered during operation, the DC load current will take a particular and well-defined value for each load voltage Veo. By using Eq. (10), and (20), it is possible to derive the relation berween the load current and the control variables $D$ or 8 .

$L=(V / X) \cdot(\mathrm{V} / \mathrm{V}$ co $) \cdot \tan (8)$

$\mathrm{L}=D \cdot(\mathrm{V} / X) \cdot \sin [\arccos (\mathrm{V} /(D \cdot \mathrm{Vco}))]$

Fig. 7 shows the constraint relation between the control variables 8 and $D$ for different $D C$ voltages. It can be seen that, for low values of $D C$ load voltage $V_{c 0}$, the system can not satisfy unity power factor operation, where the modulation index $D$ is limited by the nature of the power circuit.

Also, Fig. 8 shows the system capability for controlled current operation under unity power factor condition. To increase the absolute DC load current capability under unity power factor and certain $D C$ voltage $V_{C O}$, the $A C$ side inductance should be decreased.

This analysis is helpful for understanding easily the converter capability and its relations with the parameters that are necessary for system design stage.

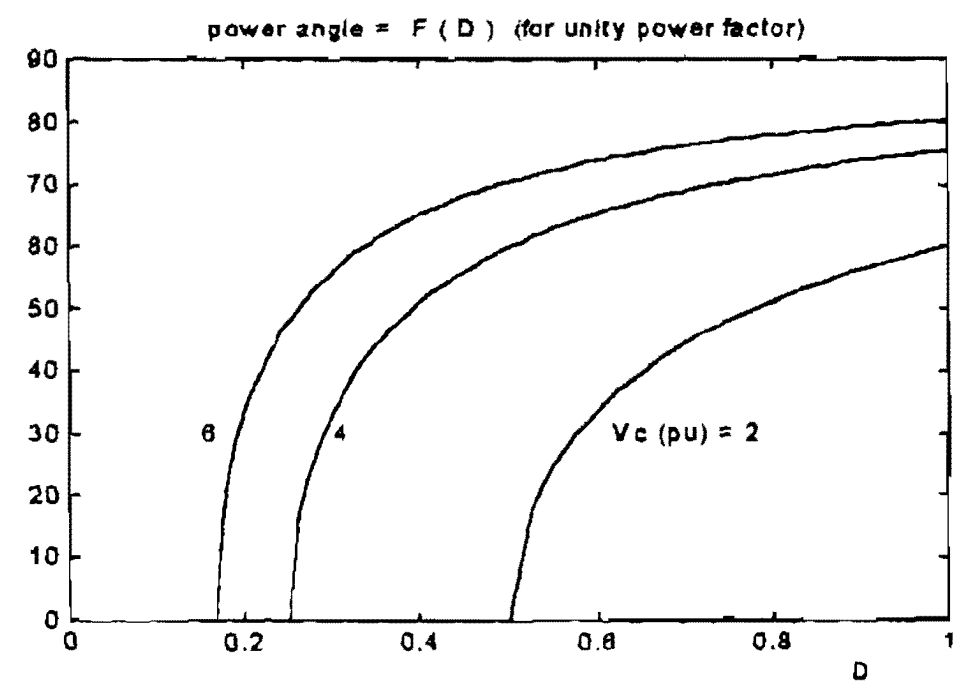

Figure 7: Control variables relation (dynamic load). 

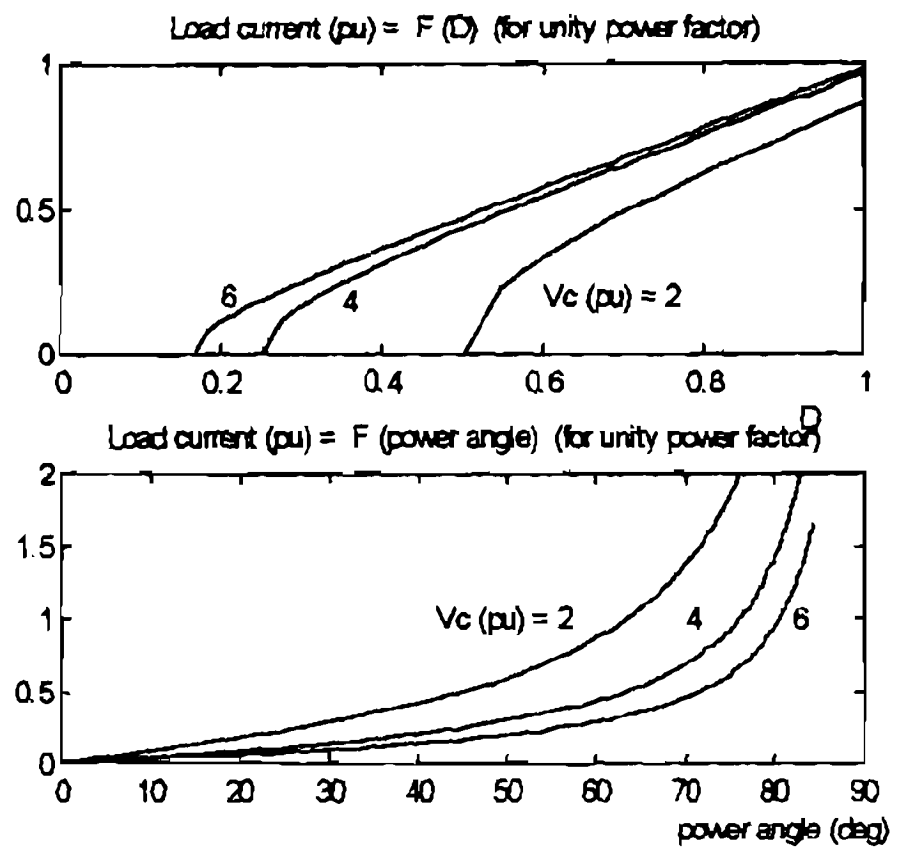

Figure 8: Load current and voltage capability of the converter (dynamic load).

\section{ZERO REACTIVE POWER CONTROLLER}

Using the characteristics explained before, different control method can be proposed to achieve the desired requirernents as shown in Fig. 9 and 10. The DC load current can be kept close to the reference by using the exror signal between that current and the reference. This error either controls directly the $A C$ input curreats or the converter terminal modulated voltage $\mathrm{Vm}$. In both cases, the control variables $D$ and $\delta$ are used to satisfy the operation requirements.

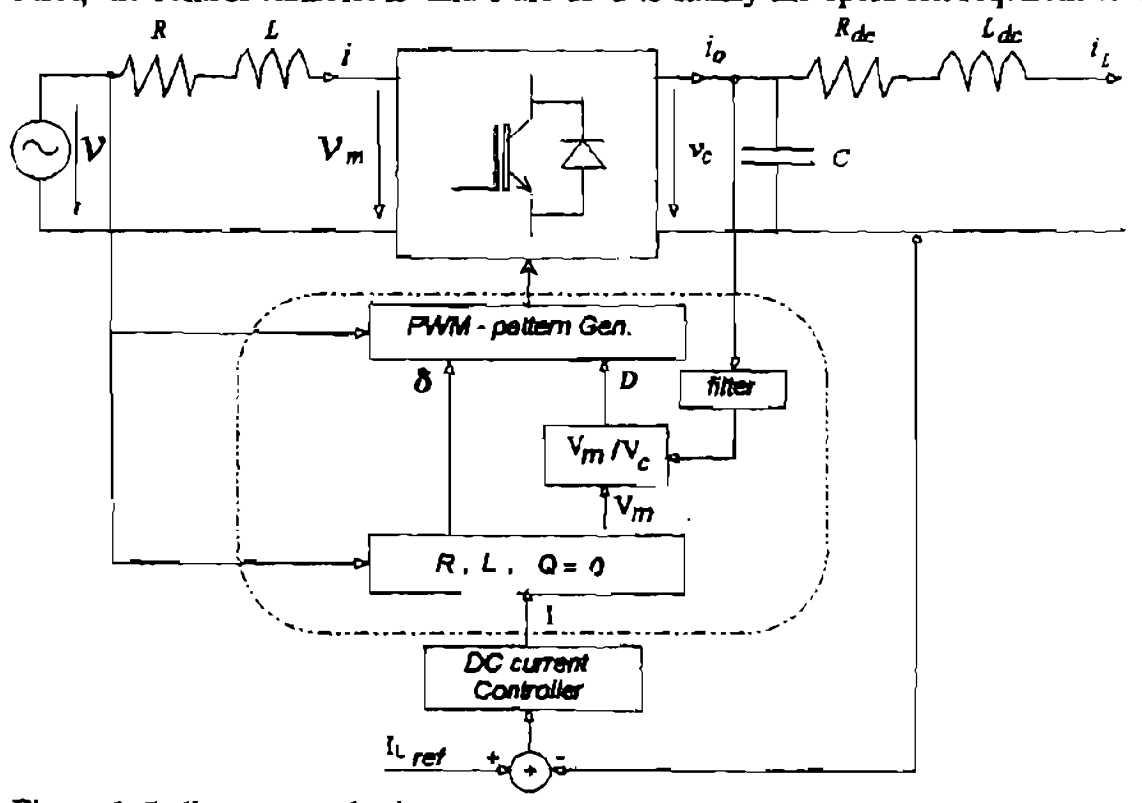

Figure 9: Indirect control scheme. 
Fig 9 shows a controller structure that can control the output DC current indirectly. For the indirect control method, the reference input $\mathrm{AC}$ current is calculated and then the required $\mathrm{Vm}$. The control variable $D$ is determined according to the average $D C$ voltnge $V_{c 0}$. The modulator uses these values to generate the PWM sovitching partern that satisfies the requirements. This method needs on-line calculation that leads to time delay. Moreover it requires accurate values of the system parameters that may changes with time.

The direct method shown in Fig 10 uses an AC current controller that forces the power circuit to draw a current close to the reference one. This AC current controller generates automatically the required PWM pattern. In this work an intelligent simple frysteresis current controller proposed in [15] is used. This controller is based on the to called freepolar modulation method. It can control the current ripple by efficient switching frequency and has excellent dynamic performance. The reference current is generated according to the source voltage template and the amplitude produced by the DC current controller. This method is very simple because there are no complex on-tine computations. Beside that there are no need for systern parameters where the system adapts itself for any parameter changes.

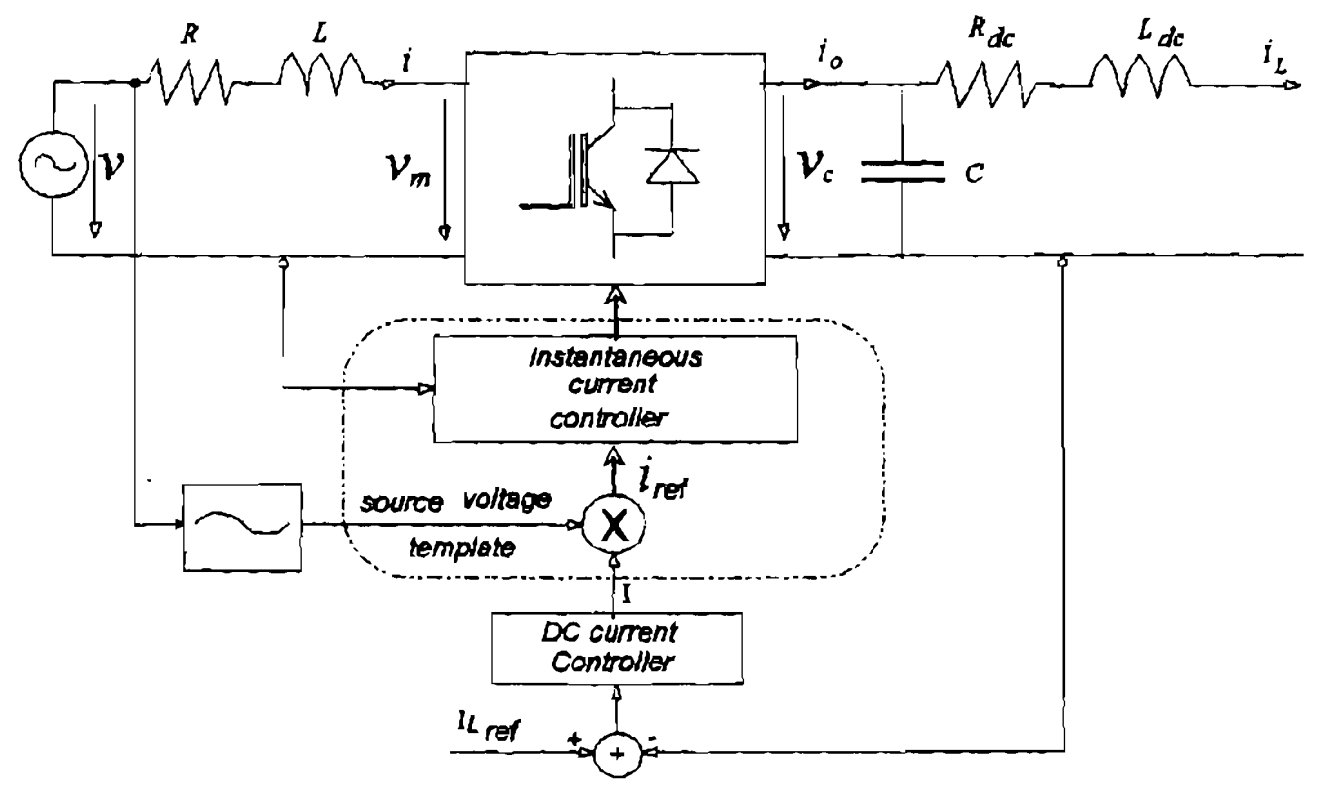

Figure 10: Proposed direct control scheme.

\section{VERIFICATION}

The system is verified in time domain by means of a pridely used industry standard device level Pspice progran. The proposed PWM converter scheme in Fig. 10 is implemented including real control circuit, drivers, snubber circuit with the following main parameters.

$\mathrm{V}=65 \mathrm{v}, 50 \mathrm{~Hz}, R=1 \mathrm{ohm}, L=10 \mathrm{mH}$,

$V_{c} O=220 \mathrm{v}, R_{d c}=0.5 \mathrm{ohm}, L d c=0.2 \mathrm{H}, C=2000 \mathrm{uF}$

Fig. 11-a and $b$ show the behavior of the system in case of rectifier and inverter operations for the same parameters. It can be observed that the AC input current is an active sinusoidal 
current with very low amplitude of ripples in both operations. Also, the control system adapts the power angle and the switching pattern automatically to keep the $A C$ line current close to the reference for both cases. Regarding the DC side, it is clear that the current source $i_{0}$ is a unidirectional pulse width modulated segments of the AC current $i$.

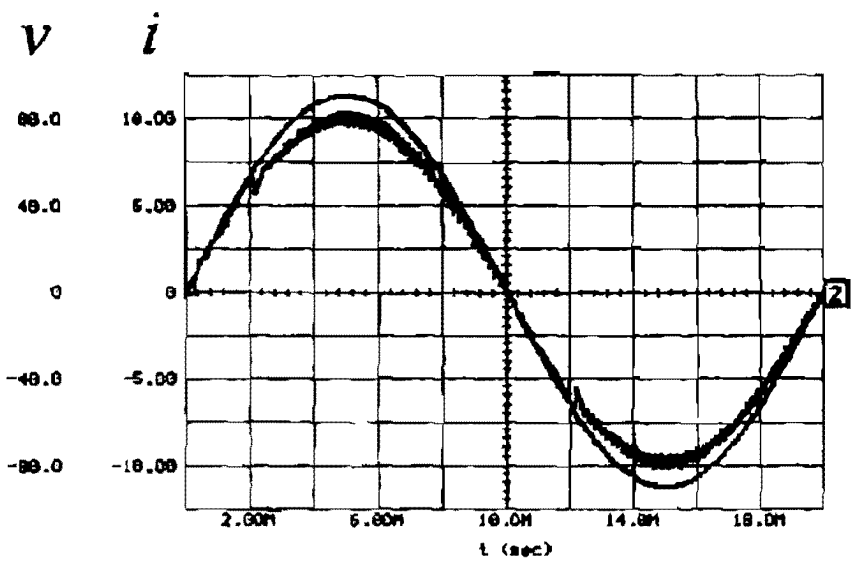

$\mathcal{V} \quad \mathcal{V}_{\mathrm{m}}$
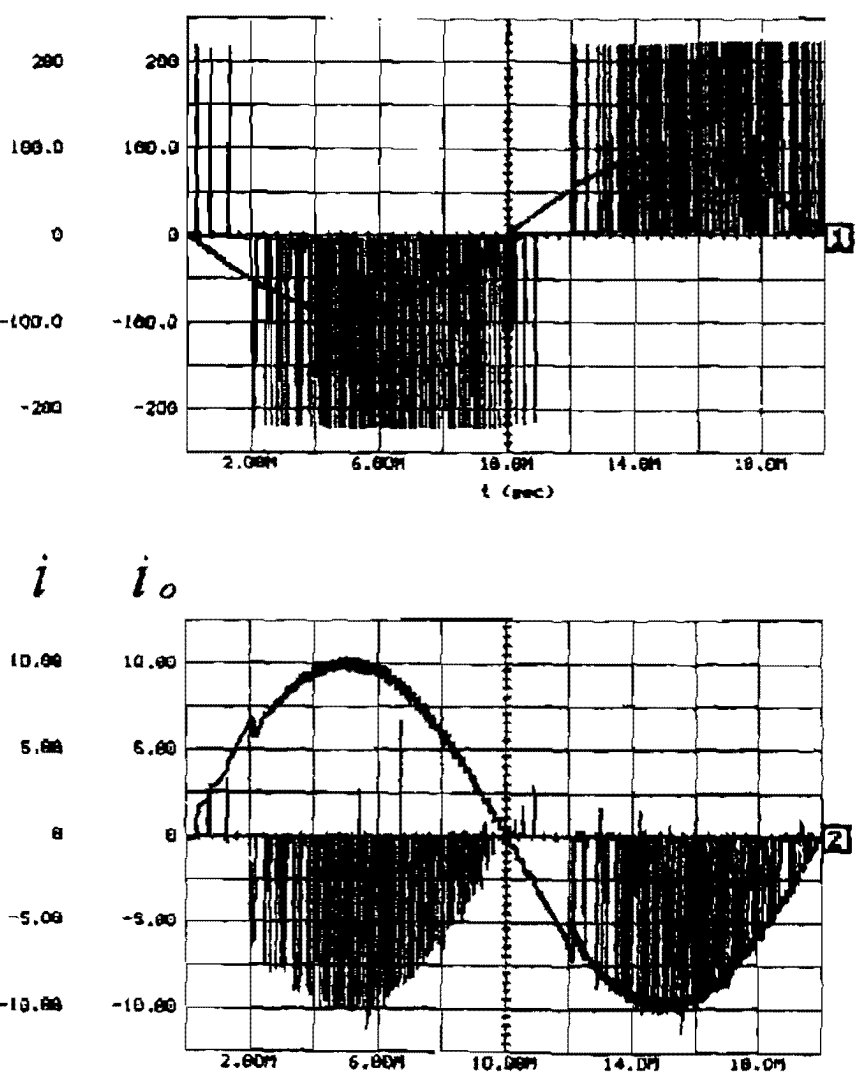

Figure 11-(a): Rectifier performance. 

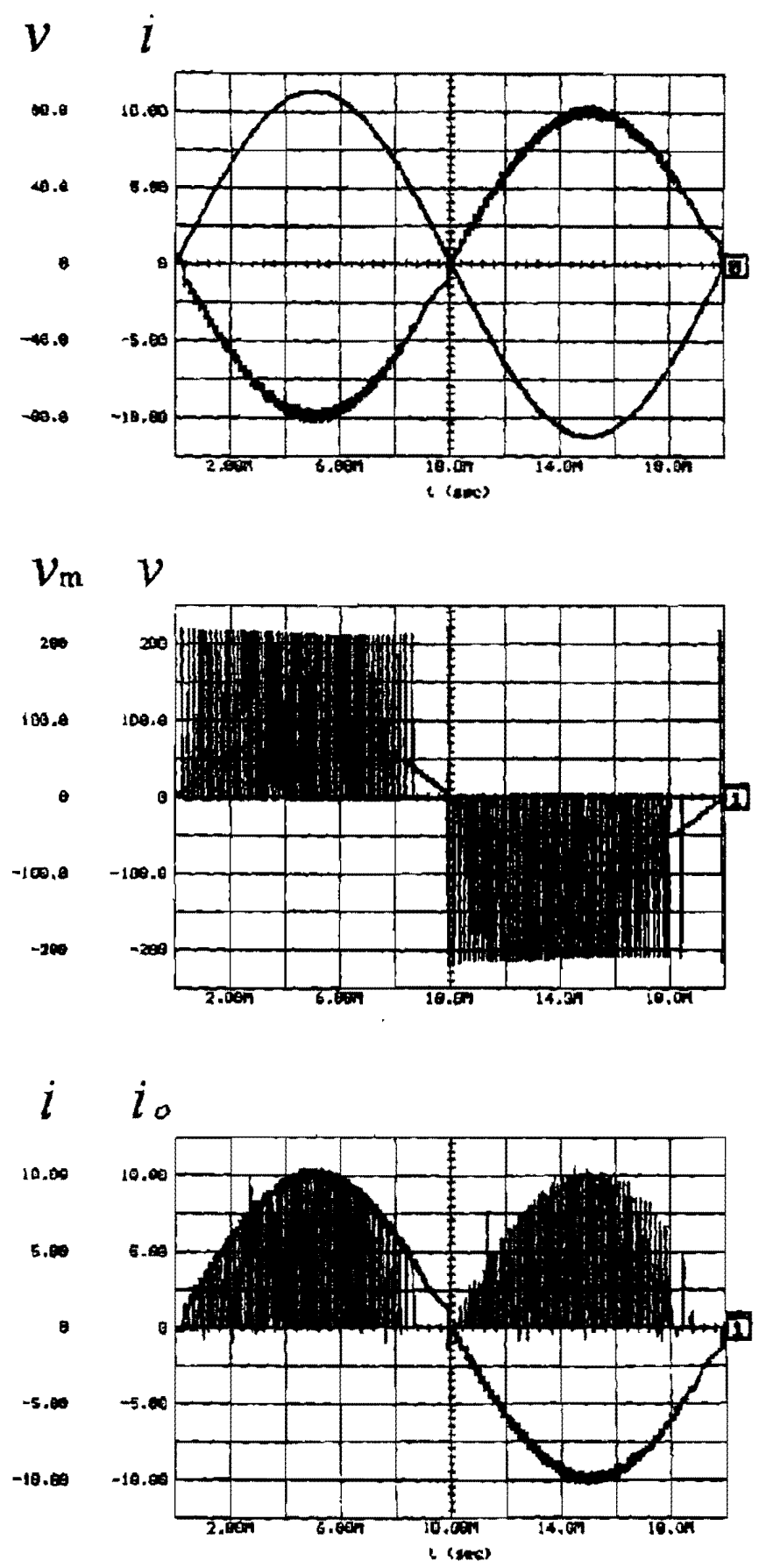

Figure 11-(b): Inverter performance. 


\section{CONCLUSION}

A novel AC/DC PWM controlled converter, controlled instantaneously, is developed and implemented. A high degree of controllability is obtained by using a simple control strategy. The principles of optration are described and design expressions are derived. Several new facts are identified and contributed. The DC current can be controlled in a certain range that depends on the system design parameters. The unity power factor operation can be obtained when the constant $a=(R L / X) . D^{2}$ mox is lagger than 2 in case of resistive loads and when the constant $b=(\mathrm{Vco} / \mathrm{V})$. Dmox is langer than 1 in case of dynarmic loads.

The presented analysis shows that the relations between the control variables $D, \delta$ and $D C$ load cursent for unity power factor are nonlinear. Therefore it is difficult to achieve the requimements using on line computations. This problem is solved here by using a self adaptive instantaneous current controller for AC current. Then, without computations for PWM patterns and with only building the desined $A C$ current wave that has the source voltage template, the DC load current can be controlled with input sinusoidal active current. With simple control structure, the converter achieves high performance such as: unity power factor operation for rectifier and inverter operation, controlled ripple for the demanded sinusoidal bine current, and output controlled DC current source as well as minimum converter loss. Other interesting characteristies are: 1) the robustness to parametric variations and disturbances; 2) the input power factor can be abitranly controlled; 3) full unilization of the porver circuit through simultaneous control of the modulation index $D$ and the power angle $\delta$.

Further research is required to handle the remaining step in perfecting the stand-alone PWM converter. Which allows the converter to operate under maximum power factor when it is beyond the unity power factor range.

\section{REFERENCES}

[1] Duke, RM, and Round, S. D., "The Steady -State Performance of a Controlled Current Active Filter" IEEE Trans. Power Electron., 1993, vol. 8, no. 2, pp. 140-146

[2] Harmens, G.L., and Enstin, J.H.R, "Real-tine Dynamic Control of Dynamic Power Filter in Supplies with High Contamination" IEEE. Trans.Power Electron. Vol. 8, No. 3, 301-308, 1993.

[3] Bhavaraju, V.B., and Enjeti, P.N., "Anatysis and Design of an Active Power Filter for Balancing Unbalanced Loads" IEEE Trans.Power Electron. Vol. 8, No. 4, 640-647, 1993.

[4] Chicharo, J.F., Dejsakulrit D., and Perera, S.P., "A Centroid Based Switching Strategy for Active Power Filters" IEEE Trans.Power Electron. Vol 8, No. 4, 648-653, 1993.

[5] Nastran, J., Cajhen, R., Seliger, M, and Jereb, P., "Active Power Filter for Nonlinear AC Loads" IEEE Trans.Powet Electron. Vol. 9, No. 1, 92-96, 1994.

[6] Ooi, B.T., and Dai, S.Z., "Series-Type Solid-State Static VAR Compensator" IEEE Trans.Power Electron. Vol. 8, No. 2, 164-169, 1993.

[7] Enjeti, P.N., and Choudhury, S.A," A New Control Strategy to Improve the Performance of a PWM AC to DC Converter under Unbalanced Operating Conditions" IEEE Trans.Powet Electron. Vol. 8, No. 4, 495-500, 1993.

18] Shirahama, H., Sakurai, Y., Matsuda, Y., Ishigaki, Y., and Murai, K, Instantaneous Control Method with a GTO Converter for Active and Reactive Powers in Superconducting Magnetic Energy Storage" IEEE Trans.Power Electron. Vol. 9, No. 1, 1-6, 1994.

[9] Trzynadlowski, A. M, and Logorski, S., "Application of Neural Networks to the Optimal Control of Three-Phase Voluge-Controlled Inverters" IEEE Trans.Power Electron. Vol. 9, No. 4, 397-404, 1994.

[10] Wang, X., Ooi, B.T., "Unity PF Current-Source Rectifier Based on Dynamic Trilogic PWM" IFEE Trans.Power Electron. Vol. 8, No. 3, 288-294, 1993.

[11] Wang, X., Ooi, B.T., "Real-Time Mult-DSP Control of Three-Phase Current-Source Unity Power Factor PWM Rectifier" IEEE Trans.Power Electron. Vol 8, No. 3, 295-300, 1993. 
[12] Zhang Z.C., and Ooi, B.T. "Multimodulator Current-Source SPWM Converters for Superconducting a Magnetic Energy Storage System" IEEE Trans.Power Electron. Vol. 8, No. 3, 250-256, 1993.

[13] Bertini, S., Ghiara T. and Marchesoni, M., "ACDC/AC High Voltage Traction Drives with Quasi-Zero Reactive Power Demand" IEEE Trans.Power Electron. Vol. 8, No. 4, 632649, 1993.

[14] Veas, D.R., Dixon, J.W., and Ooi, B.T.."A Novel Load Current Control Method for a Leading Power Factor Voltage Source PWM Rectifier." IEEE Trans.Power Electron. Vol. 9, No. 2, 153-159, 1994.

[15] EL-Sayed, Ib.F., "A powerful and efficient hysteresis PWM controlled inverter" EPE Joumal, Vol. 4, no. 4, PP. 27-33, 1994. 